\title{
Lactase persistence genotypes and malaria susceptibility in Fulani of Mali
}

\author{
A Inkeri Lokki ${ }^{*}$, Irma Järvelä ${ }^{2,3}$, Elisabeth Israelsson ${ }^{4,5}$, Bakary Maiga $^{5,7}$, Marita Troye-Blomberg ${ }^{5}$, Amagana Dolo $^{7}$, \\ Ogobara K Doumbo ${ }^{7}$, Seppo Meri ${ }^{1,3}$, Ville Holmberg ${ }^{1,6}$
}

\begin{abstract}
Background: Fulani are a widely spread African ethnic group characterized by lower susceptibility to Plasmodium falciparum, clinical malaria morbidity and higher rate of lactase persistence compared to sympatric tribes. Lactase non-persistence, often called lactose intolerance, is the normal condition where lactase activity in the intestinal wall declines after weaning. Lactase persistence, common in Europe, and in certain African people with traditions of raising cattle, is caused by polymorphisms in the enhancer region approximately $14 \mathrm{~kb}$ upstream of the lactase gene.

Methods: To evaluate the relationship between malaria and lactase persistence genotypes, a 400 bp region surrounding the main European $C / T_{-13910}$ polymorphism upstream of the lactase gene was sequenced. DNA samples used in the study originated from 162 Fulani and 79 Dogon individuals from Mali.
\end{abstract}

Results: Among 79 Dogon only one heterozygote of the lactase enhancer polymorphism was detected, whereas all others were homozygous for the ancestral $\mathrm{C}$ allele. Among the Fulani, the main European polymorphism at locus $C / T_{-13910}$ was by far the most common polymorphism, with an allele frequency of 37\%. Three other singlenucleotide polymorphisms were found with allele frequencies of 3.7\%, 1.9\% and 0.6\% each. The novel DNA polymorphism T/C -13906 was seen in six heterozygous Fulani. Among the Fulani with lactase non-persistence CC genotypes at the $C / T_{-13910}$ locus, $24 \%$ had malaria parasites detectable by microscopy compared to $18 \%$ for lactase persistent genotypes $(P=0.29)$. Pooling the lactase enhancer polymorphisms to a common presumptive genotype gave $28 \%$ microscopy positives for non-persistent and $17 \%$ for others $(P=0.11)$.

Conclusions: Plasmodium falciparum parasitaemia in asymptomatic Fulani is more common in individuals with lactase non-persistence genotypes, but this difference is not statistically significant. The potential immunoprotective properties of dietary cow milk as a reason for the partial malaria resistance of Fulani warrant further investigation.

\section{Background}

During the last 10,000 years protection against malaria and lactase persistence have been two of the strongest selection forces shaping the human genome [1,2]. Protection against malaria has been important particularly in the holoendemic regions of tropical Africa. On the other hand, lactase persistence, allowing adults to drink milk, has been shown to be beneficial in all regions where the climate and environment have made it possible to herd dairy cattle [1]. In Western Africa, these two environmental forces of selection have converged as the

\footnotetext{
* Correspondence: inkeri.lokki@helsinki.fi

'Department of Bacteriology and Immunology, Haartman Institute, P.O. Box 21, FIN-00014, University of Helsinki, Finland

Full list of author information is available at the end of the article
}

nomadic Fulani people have settled in i.e. Mali, Guinea Conakry, Senegal, Gambia and Burkina Faso.

The Fulani are traditionally a nomadic, pastoralist, trading people, herding cattle, goats and sheep across the vast dry hinterlands of their domain, where they live in sympatry with the local agricultural populations. As lactose tolerance is generally rare among African ethnic groups, the Fulani with around 50\% clinical lactose tolerance are an obvious exception among their sympatrics [3-5].

Lactase non-persistence (adult-type hypolactasia, "lactose intolerance") is a genetically determined normal trait where down-regulation of lactase activity occurs during childhood [6]. Mutations to tolerate milk lactose have occurred in human history enabling adults to use dairy products. Several single nucleotide polymorphisms

\section{Biomed Central}

(C) 2011 Lokki et al; licensee BioMed Central Ltd. This is an Open Access article distributed under the terms of the Creative Commons Attribution License (http://creativecommons.org/licenses/by/2.0), which permits unrestricted use, distribution, and reproduction in any medium, provided the original work is properly cited. 
have been identified to be associated with lactase persistence in the enhancer region residing $13.9 \mathrm{~kb}$ upstream of the lactase gene $(L C T)$ at 2q21-22 [3,7-10].

Fulani people have been shown to be more resistant to malaria infection compared to other sympatric tribes in Western Africa [11]. Some differences in the immune responses have been shown, but still the complete explanation of this phenomenon has remained unsolved.

The hypothesis of this study postulates that the partial malaria resistance could be associated to the dietary habits of the Fulani. Fulani has a tradition of abundant milk consumption and are known to use more milk than sympatric tribes. In the study area the Dogon also use milk, but not as much as the Fulani. To test this hypothesis, the 400 bp region covering the known lactase persistence variants was screened and the association between lactase persistence genotypes and malaria indices in 162 Fulani and 79 Dogon individuals was analysed.

\section{Methods}

\section{Study area and population}

The field study was carried out in rural villages located in the district of Koro where the Fulani and Dogon live in sympatry. The study villages are located in Sahelian area in Mali, the area is situated halfway between Mopti and the country border to Burkina Faso, approximately 850 kilometre North-East of Bamako, the capital city of Mali. The Malaria Research \& Training Center of the University of Bamako has established a permanent community based health centre in the village of Manteau. The area is mesoendemic for malaria and infections are mainly caused by $P$. falciparum. There is a dry season from October to May and a rainy season between June and September, leading to seasonal transmission of malaria, with most cases registered from July until December. Entomological assessment in September 2001 revealed the same entomological inoculation rate (EIR) of 0.38 infective bites/person/night in the two ethnic groups [12].

\section{Sample collection and clinical data}

Blood samples from 162 Fulani and 79 Dogon individuals from an age and gender matched control cohort were collected in a cross-sectional study during the rainy season in 2005 as previously described [13,14]. The ethical committee of the Faculty of Medicine and Pharmacy, University of Bamako in Mali and the National Ethics Committee in Sweden approved the study. Informed consent of all participants or their parents was obtained. Power calculations of this sample size with 162 Fulani showed that an odds ratio larger than 2.7 would be significant.

\section{Malaria diagnosis}

Thick blood smears were collected from all patients and stained with $3 \%$ Giemsa. Smears were read by microscopists. The number of parasites present per 300 leukocytes was counted and parasite density assuming mean leukocyte count was calculated. Study participants had several indices recorded including age, body temperature, occurrence of spleen enlargement as observed by palpation. Furthermore, haemoglobin levels and presence of Plasmodium genetic material was assessed from blood samples by polymerase chain reaction (PCR). As markers for repeated or chronic malaria infections, the genotype groups for presence of splenomegaly and anaemia (defined as hemoglobin less than $110 \mathrm{~g} / \mathrm{L}$ ) were compared. The material for this study was a cross-sectional cohort, and thereby the malaria positives cases represent asymptomatic parasitaemia, not clinical disease.

\section{Genotyping}

DNA was extracted from filter papers using Chelex-100 method $[13,15]$. Briefly, three discs of peripheral blood soaked dry filter paper were pierced out and incubated in $0.5 \%$ saponin PBS (phosphate buffered saline) solution at $4^{\circ} \mathrm{C}$ overnight. The following day filter papers were washed in PBS at $4^{\circ} \mathrm{C}$ for $15-30 \mathrm{~min}$, whereafter they were boiled in 5\% Chelex-100 water solution for $15 \mathrm{~min}$. Following vortexing for $30 \mathrm{~s}$, samples were centrifuged at 10,000 rpm for $3 \mathrm{~min}$. Supernatants containing DNA were then extracted and stored at $-20^{\circ} \mathrm{C}$.

The DNA fragment covering $400 \mathrm{bp}$ around the original lactase persistence variant $\mathrm{C} / \mathrm{T}_{-13910}$ in intron 13 of the MCM6 gene $13.9 \mathrm{~kb}$ upstream of the lactase gene [7] was amplified by PCR. Amplified fragments were sequenced. Primers 5'-CCTGGTTAATACCCACTGACCTA-3'for forward sequence and 5'-GTCACTTTGATATGATGAGAGCA-3'for reverse sequence were used in a reaction of 30 cycles using temperatures of $94^{\circ} \mathrm{C}$ for $30 \mathrm{~s}, 53^{\circ} \mathrm{C}$ for $30 \mathrm{~s}$, and $72^{\circ} \mathrm{C}$ for $75 \mathrm{~s}$ following initial $10 \mathrm{~min}$ step at $94^{\circ} \mathrm{C}$ and proceeding final step of $10 \mathrm{~min}$ at $72^{\circ} \mathrm{C}$. Amplitaq Gold (Applied Biosystems) enzyme was used in all reactions. PCR products were controlled for success of amplification on a $1.5 \%$ agarose gel containing ethidium bromide.

Samples were purified from excess primers by digestion using 2.5 U of Shrimp Alkaline Phosphatase USB and $5 \mathrm{U}$ of Exonuclease I (New England Biolabs) in $37^{\circ} \mathrm{C}$ for 60 minutes preceding inactivation of 15 minutes at $80^{\circ} \mathrm{C}$. Purified samples were prepared for sequencing using the BigDye 3.1 terminator (Applied Biosystems) as instructed by manufacturer. Sequencing reaction was as follows: initiating step of $96^{\circ} \mathrm{C}$ for $1 \mathrm{~min}, 25$ cycles of $96^{\circ} \mathrm{C}$ for $10 \mathrm{sec}, 53^{\circ} \mathrm{C}$ for $5 \mathrm{sec}, 60^{\circ} \mathrm{C}$ for $4 \mathrm{~min}$. Sequence samples were purified with Millipore Multiscreen plates 
(Millipore, USA) with Sephadex G-50 Superfine sepharose (Amersham Biosciences, Sweden), electrophoresis with an ABI 3730 DNA Analyzer (Applied Biosystems) and base calling using the Sequence Analysis 5.2 software (Applied Biosystems). The results were analysed by Sequencher 4.1.4 software (Gene Codes, USA).

\section{Statistics}

Each of the malaria variables were grouped into two categories enabling application of chi square test of statistical significance for all variables. Power calculations for the sample size were done assuming a prevalence of P. falciparum parasitaemia of $25 \%$ in unexposed (lactase non-persistent). The calculations were done for a significance of $95 \%$ and a power of $80 \%$. Statistical analyses were conducted using SPSS 15.0 for Windows (SPSS Inc.) and StatCalc EpiInfo version 6 (CDC). Mann-Whitney U-test was used for comparing parasite densities for different genotypes, which did not follow normal distribution.

\section{Results}

The enhancer region $14 \mathrm{~kb}$ upstream of the lactase gene, where the previously identified functional polymorphisms are located, was sequenced. In populations with European origin, $\mathrm{C} / \mathrm{T}_{-13910}$ is the main causative mutation for lactase persistence [7]. In Africa, several polymorphisms in the enhancer region of the lactase gene have been suggested to be associated with lactase persistence (Figure 1).

In the sequenced region, four single nucleotide polymorphisms (SNP) were detected in the Fulani and Dogon under investigation (Table 1 ). $\mathrm{C} / \mathrm{T}_{-13910}$ mutation, which is rare in most African populations, was found with a frequency of $37 \%$ in Fulani. Previously it has been detected with a minor allele frequency of $48 \%$ in Fulani from Sudan [4].

The mutation G/A-14107 previously reported in Ghana [16] had a minor allele frequency of $3.7 \%$ among Fulani. $\mathrm{G} / \mathrm{A}_{-13915}$ is the founder lactase persistence variant among Urban Saudi population [8], and was seen in two heterozygote Fulani. One novel DNA polymorphism, C/ $\mathrm{T}_{-13906}$, in the immediate proximity of the main European mutation, was found in six of the Fulani samples.

Of the 79 individuals belonging to the Dogon ethnic group, only one individual had a variant in the analysed region. This was a heterozygote of the globally most common mutation $\mathrm{C} / \mathrm{T}$ at locus -13910 .

To assess the hypothesised association between lactase persistence and malaria, the occurrence of the main functional $\mathrm{C} / \mathrm{T}_{-13910}$ variant in Fulani was analysed (Table 2). At this locus, CC corresponds to lactase nonpersistence, and both $\mathrm{CT}$ and TT to lactase persistence [7]. Among the Fulani with the CC genotype, $24 \%$ had

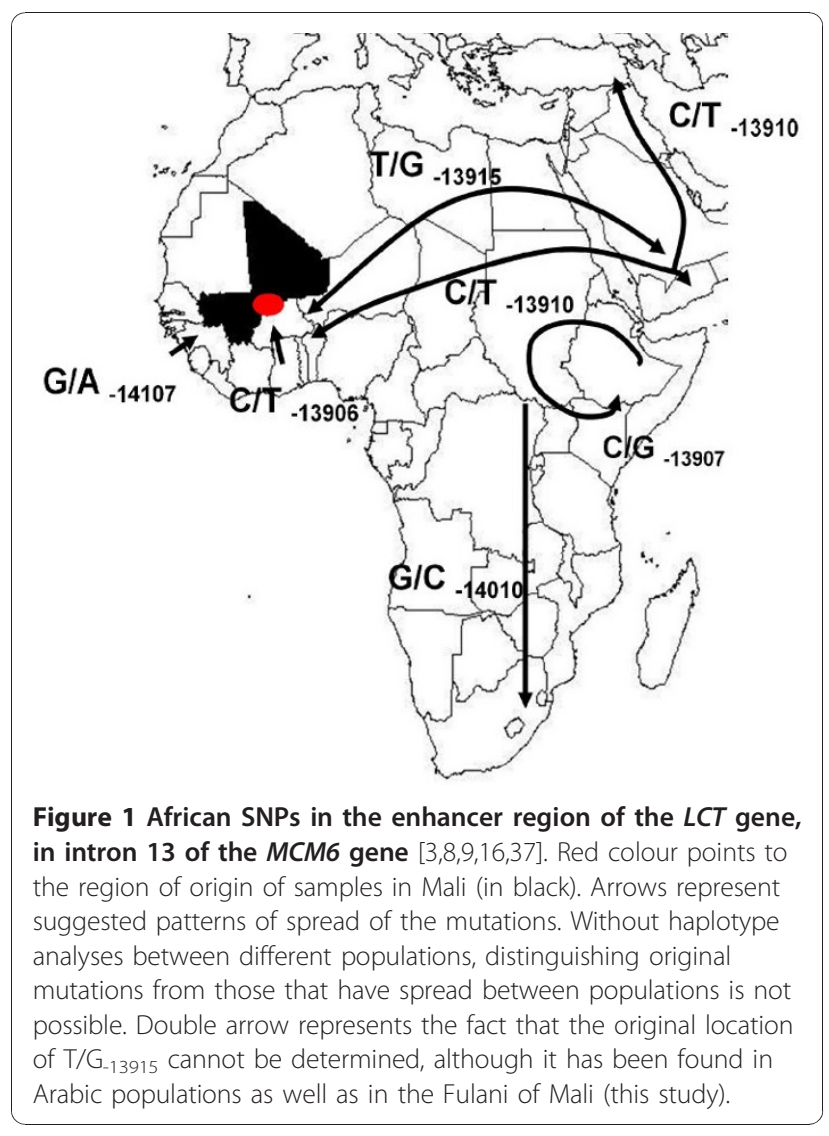

Table 1 The occurrence of four SNPs identified in this study in two ethnic tribes of Mali. $\mathbf{N}$ is the number of subjects with the given genotype

\begin{tabular}{|c|c|c|c|c|c|c|}
\hline \multirow[b]{3}{*}{ Ethnicity } & \multirow[b]{3}{*}{$N$} & \multicolumn{5}{|c|}{ C/T -13910 rs4988235 } \\
\hline & & \multicolumn{3}{|c|}{ No. with Genotype } & \multicolumn{2}{|c|}{ Allele Frequency (\%) } \\
\hline & & CC & $C T$ & $\Pi \mathrm{T}$ & C & $\mathrm{T}$ \\
\hline Fulani & 162 & 65 & 74 & 23 & 63.0 & 37.0 \\
\hline \multirow[t]{3}{*}{ Dogon } & 79 & 78 & 1 & 0 & 99.4 & 0.6 \\
\hline & & \multicolumn{5}{|c|}{$G / A_{-14107}$ rs56150605 } \\
\hline & & \multicolumn{3}{|c|}{ No. with Genotype } & \multicolumn{2}{|c|}{ Allele Frequency (\%) } \\
\hline Ethnicity & $N$ & $\overline{\mathrm{GG}}$ & GA & AA & $\mathrm{G}$ & A \\
\hline Fulani & 162 & 150 & 12 & 0 & 96.3 & 3.7 \\
\hline \multirow[t]{3}{*}{ Dogon } & 79 & 79 & 0 & 0 & 100.0 & 0.0 \\
\hline & & \multicolumn{5}{|c|}{$T / C_{-13906}$ New SNP } \\
\hline & & \multicolumn{3}{|c|}{ No. with Genotype } & \multicolumn{2}{|c|}{ Allele Frequency (\%) } \\
\hline Ethnicity & $N$ & $\bar{\pi}$ & $\mathrm{TC}$ & $\mathrm{CC}$ & $\mathrm{T}$ & C \\
\hline Fulani & 162 & 156 & 6 & 0 & 98.1 & 1.9 \\
\hline \multirow[t]{3}{*}{ Dogon } & 79 & 79 & 0 & 0 & 100.0 & 0.0 \\
\hline & & \multicolumn{5}{|c|}{$\mathrm{T}_{\mathrm{G}} \mathrm{G}_{-13915}$ rs41380347 } \\
\hline & & \multicolumn{3}{|c|}{ No. with Genotype } & \multicolumn{2}{|c|}{ Allele Frequency (\%) } \\
\hline Ethnicity & $N$ & $\bar{\pi}$ & TG & GG & $\mathrm{T}$ & G \\
\hline Fulani & 162 & 160 & 2 & 0 & 99.4 & 0.6 \\
\hline Dogon & 79 & 79 & 0 & 0 & 100.0 & 0.0 \\
\hline
\end{tabular}


Table 2 Plasmodium falciparum parasitaemia in asymptomatic Fulani individuals grouped by observed genotype

\begin{tabular}{|c|c|c|c|c|}
\hline & Lactase Non-persistence & Lactase persistence & $P$-value & OR $(95 \% \mathrm{Cl})$ \\
\hline Fulani samples & $C_{-13910}$ & $\mathrm{CT} / \mathrm{TT}{ }_{-13910}$ & & \\
\hline Malaria PCR positive, $\mathrm{n}(\%)$ & $39 / 65(60 \%)$ & $50 / 97(51 \%)$ & 0.29 & $1.41(0.71-2.80)$ \\
\hline Malaria microscopy positive, n (\%) & $15 / 65(23 \%)$ & $17 / 94^{*}(18 \%)$ & 0.44 & $1.36(0.58-3.18)$ \\
\hline Fulani samples & Wild-type & Combined lactase persistence & & \\
\hline Malaria PCR positive, $\mathrm{n}(\%)$ & $28 / 51(55 \%)$ & $61 / 111(55 \%)$ & 0.99 & $1.00(0.49-2.05)$ \\
\hline Malaria microscopy positive, n (\%) & $14 / 51(28 \%)$ & $18 / 108^{*}(17 \%)$ & 0.11 & $1.89(0.79-4.51)$ \\
\hline
\end{tabular}

*Microscopy data missing for three individuals.

malaria parasites present in the peripheral blood detectable with microscopy compared to $18 \%$ of those with genotypes CT/TT $(\mathrm{P}=0.19$, odds ratio 1.70 , $95 \%$ confidence interval 0.72-4.03). The diagnostic PCR for P. falciparum was positive in $60 \%$ of subjects with lactase non-persistence (CC) and in 51\% of lactase persistence $(\mathrm{CT} / \mathrm{TT})(\mathrm{P}=0.29$, OR 1.41, 95\% CI 0.71-2.80).

Among the subjects with the CC genotype, splenomegaly was seen in $39 \%(25 / 65)$ and among the TC/TT genotypes in 35\% (34/97) of the Fulani. Anemia was present in 56\% (36/64) of CC individuals and in 58\% (56/97) of TC/TT individuals. These differences were not statistically significant $(\mathrm{p}>0.05)$.

Parasite densities of the Fulani positive for P. falciparum with microscopy were compared with different genotypes. The mean parasite density for the lactase non-persistance CC-13910 genotypes was 4,755 parasites $/ \mu \mathrm{L}$ and for the CT/TT-13910 genotypes 2,584 parasites $/ \mu \mathrm{L}(\mathrm{p}=0.56$, Mann-Whitney U-test). The geometric means were 1,290 parasites/ $\mu \mathrm{L}$ and 1,360 parasites $/ \mu \mathrm{L}$, respectively.

Assuming that all the detected SNPs in the lactase enhancer region would be functional, all patients with at least one polymorphic allele were pooled and then compared against the wild-type homozygotes (Table 2). The difference between at least one polymorphism in any of the loci and wild-type homozygotes was not significant either, even though a trend of more microscopy positive individuals in the lactase non-persistence group in comparison with the lactase persistence group was observed $(\mathrm{p}=0.11$, OR 1.89, 95\% CI 0.79-4.51).

\section{Discussion}

Several studies in Burkina Faso have indicated that people belonging to the Fulani tribe are less parasitized, have fewer clinical episodes of malaria, and higher levels of anti-malarial antibodies as compared to the sympatric ethnic groups Mossi and Rimabé, despite similar transmission intensity [17-21]. In Mali, Fulani have lower parasite density and are less affected by the disease compared to sympatric Dogon [22]. The more susceptible Dogon population seemed to respond to infections with pronounced splenomegaly, whereas Fulani have chronically enlarged spleens already functional for protection.

The reason for malaria resistance in Fulani is still unknown, but suggested mechanisms include a functional deficiency of regulatory $\mathrm{T}$ cells $[21]$ and different antibody- and cytokine-mediated responses [23,24]. However, not much attention has been paid to the possible role of the different diets between Fulani and sympatric tribes. The Fulani diet is known to be mainly based on cow milk and also meat consumption is high. No detailed information on dietary habits of study subjects was available, although research on the subject is underway, so local observations and general knowledge on traditions of abundant milk consumption among Fulani in Western Africa were applied as sources of dietary data on population level. In a study in Nigeria, Fulani were described to get $28-29 \%$ of their total energy intake from milk products, which would correspond to about 700 grams of milk daily [25]. This amount of milk would probably cause symptoms for lactase non-persistence adults. Thus it is likely that Fulani in Mali with lactase persistence genotypes consume more milk than those with non-persistence genotypes.

The hypothesis of the present study postulates that the increased ability to drink milk in individuals with lactase persistence genotypes may offer protection against malaria infection. In human evolution, lactase activity has been maintained by mutations in the enhancer region of the lactase gene in those populations which herd livestock and will thus benefit substantially from the ability to use dairy products as part of the adults' diet. Several such mutations have enriched over time in isolated livestock herding populations, although smaller than expected differences among these genetically diverse populations have been reported [26]. In populations with European origin, $\mathrm{C} / \mathrm{T}_{-13910}$ is the main causative mutation for lactase persistence [7]. In Africa several polymorphisms in the enhancer region of the lactase gene have been suggested to be associated with lactase persistence (Figure 1). Among the 162 Fulani genotyped, the major Caucasian mutation $\mathrm{C} / \mathrm{T}_{-13910}$ was by far the most common polymorphism with an allele 
frequency of $37 \%$. This means that $60 \%$ of the Fulani carry the lactase persistence genotype. Possibly the above described sympatry with other ethnic groups is responsible for the lower minor allele frequency found in this study than the one described by Enattah et al [4]. Three other SNPs in the region were found. They were found as heterozygotes in twelve, six and two subjects each. Among the 79 Dogon samples tested only one heterozygote of a lactase enhancer polymorphism, the main European mutation, was detected.

Results show that $P$. falciparum parasitaemia in asymptomatic Fulani is more common in individuals with lactase non-persistence genotypes. However, this finding was not statistically significant as this study did not have power to detect a difference with odds ratio smaller than 2.7. The rarity of the SNPs among Dogon and among other non-pastoralist populations in Africa further supports the hypothesis. Asymptomatic parasitaemia was used as the main phenotype, assessment of the suggested protective effects of lactase persistence on clinical malaria episodes, severe malaria or malaria mortality was not applicable. The novel $\mathrm{T} / \mathrm{C}_{-13906}$ polymorphism detected in this study cannot be claimed to be functional without lactose tolerance test or intestinal biopsy on individuals with this variant. However, the location only $4 \mathrm{bp}$ from the main mutation supports the possibility of functionality. In addition, the lack of polymorphisms in the Dogon subjects suggests that the variability in the Fulani lactase enhancer region is caused by ongoing selection for which functionality is a prerequisite.

The potential protective role of milk consumption in malaria infections has been debated for more than half a century. Studies in the 1950s indicated that a cow milk diet has a suppressive effect on malaria infections in rats, mice and monkeys [27]. The suppression of the normal replication of the parasites was suggested to be caused mainly by the deficiency of $p$-aminobenzoic acid (PABA), as milk is lacking PABA in contrast to normal diets [28]. Plasmodium species can synthesize PABA de novo, but probably not in sufficient amounts to survive without dietary intake by the host [29].

Infants under six months of age have a lower incidence of severe malaria than older children, which mainly has been explained by maternal antibodies acquired through breast-feeding. Deficiency of PABA might be another reason, especially for children exclusively breast fed. Additionally, there might be other still unidentified antimalarial properties of milk, as it consists of numerous probiotics, innate immunity components (i.e. mannose binding-lectin, properdin, interferons), cytokines, chemokines and anti-inflammatory factors [30].

The relationship between nutrition and malaria seems to be complex. In the 1990s it was suggested that lactase non-persistence would have been selected by malaria, like beta-thalassaemia and glucose 6-phosphate dehydrogenase deficiency [31,32]. This hypothesis was soon rejected, as it was based on the false assumption that the lactase persistence trait would be the wild-type allele $[33,34]$. Reduced malaria morbidity in malnourished children and malaria outbreaks following refeeding after famines in Africa has been reported [35]. However, Fulani with diets consisting mainly of milk, did not have increased incidences of severe malaria after refeeding [36].

The potential protective role against malaria infection achieved by abundant milk consumption, allowed by lactase persistence genotypes, could have many explanations. First, milk might provide a generally increased nutritional status being rich in energy, proteins and fatty acids. Secondly, milk consists of a large number of immunomodulating components. Third, a diet dominated by dairy products might lead to a relative PABA deficiency, protecting from malaria. Additionally, there might be still unrecognized factors in milk providing protection against malaria and other infections.

\section{Conclusions}

Plasmodium falciparum parasitaemia in asymptomatic Fulani is more common in individuals with lactase nonpersistence genotypes, but this difference is not statistically significant. A novel polymorphism in the $L C T$ enhancer region was discovered with potential functional importance. The lack of $L C T$ enhancer region polymorphisms in the sympatric Dogon suggests positive selection in the Fulani who have access to dietary milk. The potential immunoprotective properties of dietary cow milk as a reason for the partial malaria resistance of Fulani warrant further investigation.

\section{Acknowledgements}

The authors thank all the participants of this study. This work was supported by grants from Finska Läkaresällskapet (VH), the Finnish Cultural Foundation $(\mathrm{VH})$, the Academy of Finland (SM), and the Sigrid Jusélius Foundation (IJ), and by a grant to MTB from the Swedish Agency for Research Development with Developing Countries/Sida/SAREC). Field work at the Manteou sites is supported by grants from WHO/TDR and the BioMalPar European Network of Excellence (LSMP-CT 2004-503578) from the Priority 1 "Life Sciences, Genomics and Biotechnology for Health" in the $6^{\text {th }}$ Framework Programme.

\section{Author details}

${ }^{1}$ Department of Bacteriology and Immunology, Haartman Institute, P.O. Box 21, FIN-00014, University of Helsinki, Finland. 'Department of Medical Genetics, University of Helsinki, Helsinki, Finland. ${ }^{3}$ Laboratory Services, Helsinki University Central Hospital, Helsinki, Finland. ${ }^{4}$ Seattle Biomedical Research Institute, Seattle, USA. ${ }^{5}$ Department of Immunology, Wenner-Gren Institute, Stockholm University, Stockholm, Sweden. ${ }^{6}$ Division of Infectious Diseases, Department of Medicine, Helsinki University Central Hospital, Helsinki, Finland. ${ }^{7}$ Department of Epidemiology of Parasitics Diseases, Malaria Research \& Training Center, Faculty of Medicine, Pharmacy \& Odonto Stomatology, University of Bamako, Bamako, Mali.

\section{Authors' contributions}

IL extracted the DNA from blood samples stored in Stockholm University and performed sequencing and analysis of sequence data in University of 
Helsinki. VH introduced the original idea for study and drafted the manuscript together with IL. IJ supervised laboratory work in University of Helsinki and provided expertise in lactase genetics during writing of the manuscript. SM provided insight to the discussion of immunologic properties of milk and infection biology of malaria. El and MTB supervised laboratory work in Stockholm University. Furthermore, MTB provided the blood samples while El participated in the collection of the samples. BM, AD and OKD provided expertise of the research material, described the study population, and collaborated in organizing the field work for collecting the data. All authors read and approved of the final manuscript.

\section{Competing interests}

The authors declare that they have no competing interests.

Received: 24 September 2010 Accepted: 14 January 2011

Published: 14 January 2011

\section{References}

1. Bersaglieri T, Sabeti PC, Patterson N, Vanderploeg T, Schaffner SF, Drake JA Rhodes M, Reich DE, Hirschhorn JN: Genetic signatures of strong recent positive selection at the lactase gene. Am J Hum Genet 2004, 74:1111-1120.

2. Kwiatkowski DP: How malaria has affected the human genome and what human genetics can teach us about malaria. Am J Hum Genet 2005, 77:171-192.

3. Tishkoff SA, Reed FA, Ranciaro A, Voight BF, Babbitt CC, Silverman JS, Powell K, Mortensen HM, Hirbo JB, Osman M, et al: Convergent adaptation of human lactase persistence in Africa and Europe. Nat Genet 2007, 39:31-40.

4. Enattah NS, Trudeau A, Pimenoff V, Maiuri L, Auricchio S, Greco L, Rossi M, Lentze M, Seo JK, Rahgozar S, et al: Evidence of still-ongoing convergence evolution of the lactase persistence T-13910 alleles in humans. Am J Hum Genet 2007, 81:615-625.

5. Ransome-Kuti O, Kretchmer N, Johnson JD, Gribble JT: A genetic study of lactose digestion in Nigerian families. Gastroenterology 1975, 68:431-436.

6. Sahi T: Genetics and epidemiology of adult-type hypolactasia. Scand J Gastroenterol Suppl 1994, 202:7-20.

7. Enattah NS, Sahi T, Savilahti E, Terwilliger JD, Peltonen L, Jarvela I: Identification of a variant associated with adult-type hypolactasia. Nat Genet 2002, 30:233-237.

8. Imtiaz F, Savilahti E, Sarnesto A, Trabzuni D, Al-Kahtani K, Kagevi I, Rashed MS, Meyer BF, Jarvela I: The T/G 13915 variant upstream of the lactase gene (LCT) is the founder allele of lactase persistence in an urban Saudi population. J Med Genet 2007, 44:e89.

9. Ingram CJ, Elamin MF, Mulcare CA, Weale ME, Tarekegn A, Raga TO, Bekele E, Elamin FM, Thomas MG, Bradman N, Swallow DM: A nove polymorphism associated with lactose tolerance in Africa: multiple causes for lactase persistence? Hum Genet 2007, 120:779-788.

10. Torniainen S, Freddara R, Routi T, Gijsbers C, Catassi C, Hoglund P, Savilahti E, Jarvela I: Four novel mutations in the lactase gene (LCT) underlying congenital lactase deficiency (CLD). BMC Gastroenterol 2009, 9:8.

11. Bryceson AD, Fleming AF, Edington GM: Splenomegaly in Northern Nigeria. Acta Trop 1976, 33:185-214

12. Dolo A, Modiano D, Maiga B, Daou M, Dolo G, Guindo H, Ba M, Maiga H, Coulibaly D, Perlman H, et al: Difference in susceptibility to malaria between two sympatric ethnic groups in Mali. Am J Trop Med Hyg 2005, 72:243-248.

13. Vafa M, Maiga B, Berzins K, Hayano M, Bereczky S, Dolo A, Daou M, Arama C, Kouriba B, Farnert A, et al: Associations between the IL-4 -590 T allele and Plasmodium falciparum infection prevalence in asymptomatic Fulani of Mali. Microbes Infect 2007, 9:1043-1048.

14. Vafa M, Israelsson E, Maiga B, Dolo A, Doumbo OK, Troye-Blomberg M: Relationship between immunoglobulin isotype response to Plasmodium falciparum blood stage antigens and parasitological indexes as well as splenomegaly in sympatric ethnic groups living in Mali. Acta Trop 2009, 109:12-16.

15. Israelsson E, Ekstrom M, Nasr A, Dolo A, Kearsley S, Arambepola G, Homann MV, Maiga B, Doumbo OK, Elghazali G, et al: Marked differences in CRP genotype frequencies between the Fulani and sympatric ethnic groups in Africa. Malar J 2009, 8:136.
16. Torniainen S, Parker Ml, Holmberg V, Lahtela E, Dandara C, Jarvela I: Screening of variants for lactase persistence/non-persistence in populations from South Africa and Ghana. BMC Genet 2009, 10:31.

17. Modiano D, Petrarca V, Sirima BS, Bosman A, Nebie I, Diallo D, Lamizana L, Esposito F, Coluzzi M: Plasmodium falciparum malaria in sympatric ethnic groups of Burkina Faso, west Africa. Parassitologia 1995, 37:255-259.

18. Modiano D, Petrarca V, Sirima BS, Nebie I, Diallo D, Esposito F, Coluzzi M: Different response to Plasmodium falciparum malaria in West African sympatric ethnic groups. P Natl Acad Sci USA 1996, 93:13206-13211.

19. Modiano D, Chiucchiuini A, Petrarca V, Sirima BS, Luoni G, Perlmann H, Esposito F, Coluzzi M: Humoral response to Plasmodium falciparum Pf155/ring-infected erythrocyte surface antigen and Pf332 in three sympatric ethnic groups of Burkina Faso. American Journal of Tropical Medicine and Hygiene 1998, 58:220-224.

20. Modiano D, Petrarca V, Sirima BS, Luoni G, Nebie I, Diallo DA, Esposito F, Coluzzi M: Different response to Plasmodium falciparum in west African sympatric ethnic groups: possible implications for malaria control strategies. Parassitologia 1999, 41:193-197.

21. Torcia MG, Santarlasci V, Cosmi L, Clemente A, Maggi L, Mangano VD, Verra F, Bancone G, Nebie I, Sirima BS, et al: Functional deficit of T regulatory cells in Fulani, an ethnic group with low susceptibility to Plasmodium falciparum malaria. Proc Natl Acad Sci USA 2008, 105:646-651.

22. Bereczky S, Dolo A, Maiga B, Hayano M, Granath F, Montgomery SM, Daou M, Arama C, Troye-Blomberg M, Doumbo OK, Farnert A: Spleen enlargement and genetic diversity of Plasmodium falciparum infection in two ethnic groups with different malaria susceptibility in Mali, West Africa. Trans R Soc Trop Med Hyg 2006, 100:248-257.

23. McCall MB, Hopman J, Daou M, Maiga B, Dara V, Ploemen I, NganouMakamdop K, Niangaly A, Tolo Y, Arama C, et al: Early interferon-gamma response against Plasmodium falciparum correlates with interethnic differences in susceptibility to parasitemia between sympatric Fulani and Dogon in Mali. J Infect Dis 2010, 201:142-152.

24. Vafa M, Maiga B, Israelsson E, Dolo A, Doumbo OK, Troye-Blomberg M: Impact of the IL-4 $-590 \mathrm{C} / \mathrm{T}$ transition on the levels of Plasmodium falciparum specific lgE, lgG, lgG subclasses and total $\lg E$ in two sympatric ethnic groups living in Mali. Microbes Infect 2009, 11:779-784.

25. Glew RH, Williams M, Conn CA, Cadena SM, Crossey M, Okolo SN, VanderJagt DJ: Cardiovascular disease risk factors and diet of Fulani pastoralists of northern Nigeria. Am J Clin Nutr 2001, 74:730-736.

26. Rasinpera $H$, Savilahti E, Enattah NS, Kuokkanen M, Totterman N, Lindahl H, Jarvela I, Kolho KL: A genetic test which can be used to diagnose adulttype hypolactasia in children. Gut 2004, 53:1571-1576.

27. Maegraith $B G$, Deegan $T$, Jones ES: Suppression of malaria (P. berghei) by milk. Br Med J 1952, 2:1382-1384.

28. Hawking F: Milk, p-aminobenzoate, and malaria of rats and monkeys. $\mathrm{Br}$ Med J 1954, 1:425-429.

29. Kicska GA, Ting LM, Schramm VL, Kim K: Effect of dietary p-aminobenzoic acid on murine Plasmodium yoelii infection. J Infect Dis 2003, 188:1776-1781

30. Chirico G, Marzollo R, Cortinovis S, Fonte C, Gasparoni A: Antiinfective properties of human milk. J Nutr 2008, 138:1801S-1806S.

31. Anderson B, Vullo C: Did malaria select for primary adult lactase deficiency? Gut 1994, 35:1487-1489.

32. Meloni T, Colombo C, Ogana A, Mannazzu MC, Meloni GF: Lactose absorption in patients with glucose 6-phosphate dehydrogenase deficiency with and without favism. Gut 1996, 39:210-213.

33. Cook GC: Hypolactasia and protection against Plasmodium spp infection in Homo sapiens. Gut 1995, 37:157.

34. Auricchio S: Lactase deficiency phenotype has not been selected by malaria. Ital J Gastroenterol Hepatol 1998, 30:494-495.

35. Murray MJ, Murray AB, Murray NJ, Murray MB: Diet and cerebral malaria: the effect of famine and refeeding. Am J Clin Nutr 1978, 31:57-61.

36. Murray J, Murray A, Murray M, Murray C: The biological suppression of malaria: an ecological and nutritional interrelationship of a host and two parasites. Am J Clin Nutr 1978, 31:1363-1366.

37. Khabarova YTS, Savilahti E, Isokoski M, Mattila KJ, Jarvela I: The G/A-13914 variant upstream of the lactase gene $(\mathrm{LCT})$ is a novel variant associated with lactase persistence/non persistence. Scand J Clin Lab Invest.

\section{doi:10.1186/1475-2875-10-9}

Cite this article as: Lokki et al:: Lactase persistence genotypes and malaria susceptibility in Fulani of Mali. Malaria Journal 2011 10:9. 